DOI: $10.5007 / 2175-7941.2012 v 29 n 2 p 325$

\title{
SOBRE O TAMANHO APARENTE DA LUA NO HORIZONTE E A MAIORES ALTURAS
}

Guilherme de Almeida

Colégio Militar (atualmente professor aposentado)

Associação Portuguesa de Astrônomos Amadores (APAA)

Lisboa - Portugal

\section{Resumo}

É frequente afirmar-se que a Lua nos parece maior quando desponta no horizonte e menor quando a vemos mais alta. Todos nos apercebemos disso, mas será realidade, ilusão ou pura confusão? No presente artigo, analisaremos a variação da distância da Lua ao observador, quando ela é observada a diferentes alturas no mesmo dia, e procuraremos uma explicação para esses fatos.

Palavras-chave: Tamanho aparente da Lua. Percepção do tamanho da Lua. Distância entre o observador e a Lua. Raio da Terra. Órbita da Lua. Periodo orbital da Lua. Apogeu e perigeu lunares. Meridiano celeste local. Refração atmosférica. Refração diferencial.

\begin{abstract}
Usually everybody says that the Moon seems larger when it is very low, quite close to the horizon, and smaller when it is higher in the sky. We all "see" this, but is it pure reality, illusion or confusion? This article will analyze the variation of the distance from
\end{abstract}

\footnotetext{
About the apparent Moon size on the horizon and greater heights

* Recebido: março de 2012.

Aceito: junho de 2012.
} 
the observer to the Moon, when it is observed at different altitudes on the same day. We will look for an explanation to these facts.

Keywords: Apparent size of the Moon. Perception of the Moon size. Distance between the observer and the Moon. Earth radius. Orbit of the Moon. Moon orbital period. Moon apogee and perigee. Celestial local meridian. Atmospheric refraction. Differential refraction.

\section{Apreciação do problema}

É certo que, devido à orbita elíptica da Lua em torno da Terra, descrita em cerca de 27,3 dias, o nosso satélite passa por uma posição mais próxima da Terra (perigeu), onde nos parece maior, e por outra mais afastada (apogeu), onde é vista com menor diâmetro aparente (Fig. 5). Isso é real e mensurável, mas o objeto deste artigo é outro: referimo-nos à diferente percepção visual do diâmetro aparente da Lua, na mesma noite, a diferentes alturas em relação ao horizonte. Na verdade, em pouco mais de cinco horas, desde que a Lua nasce até que atinge a sua altura máxima na mesma noite, a distância da Terra à Lua (que é sempre entendida entre os centros destes dois astros) pouco varia. Por isso, podemos considerar, sem grande erro, tal distância como constante para um intervalo de tempo tão curto (menos de 1/100 do período orbital). Neste contexto, é lícito considerar esse troço da órbita da Lua como se fosse circular.

Muitas explicações podem ser adiantadas para a tradicional percepção de uma Lua maior, quando esta se encontra junto ao horizonte, à nascente ou à poente: pura ilusão para alguns, percepção errônea para outros, ilusão de óptica para outros ainda. Começaremos por ver como varia a distância da Lua a um observador terrestre, à medida que a Lua nasce até a sua altura máxima (passagem meridiana).

Na Fig. 1, mostram-se três posições da Lua em relação a um observador terrestre: no horizonte $(\mathrm{H})$, à distância $d_{\mathrm{H}}$ do observador; no meridiano $(\mathrm{M})$, à distância $d_{\mathrm{M}}$; no zênite $(\mathrm{Z})$, à distância $d_{\mathrm{Z}}$ do observador, em uma situação que não é possível para a latitude do território português. Por razões de clareza, a distância da Terra à Lua não foi representada à escala, embora as dimensões relativas da Terra e da Lua estejam na mesma escala. 


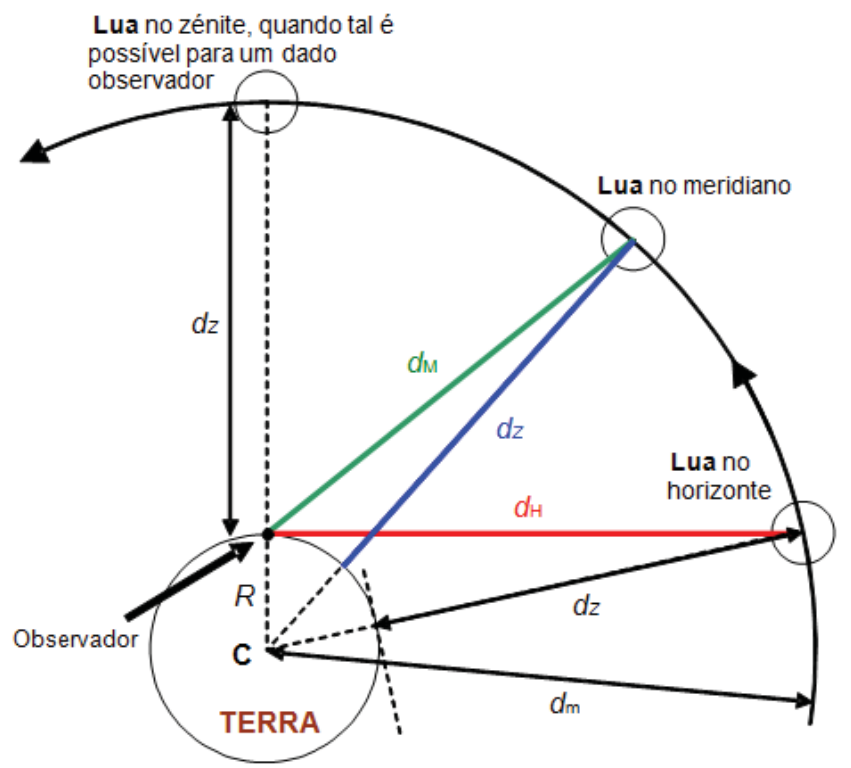

Fig. I - A Lua no horizonte, no meridiano e no zênite, para um dado observador. $R$ designa a medida do raio terrestre médio e $d_{m}$ indica a distância média, entre centros, da Lua à Terra.

Nesta figura, podemos ver que $d_{\mathrm{H}}>d_{\mathrm{M}}$, ou seja, no horizonte, a Lua está mais longe do observador do que quando se encontra no meridiano. Vemos, ainda, que $d_{\mathrm{M}}>d_{\mathrm{Z}}$ e, consequentemente, $d_{\mathrm{H}}>d_{\mathrm{Z}}$, o que significa que a Lua no meridiano está mais longe do observador do que quando está no zênite; e que a Lua no horizonte está mais afastada do observador que se estivesse no meridiano. Como o nosso planeta não é "um ponto" em relação às dimensões da órbita lunar

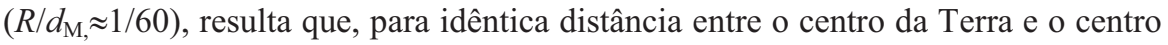
da Lua, as distâncias da Lua em relação ao observador cumprem a relação: distância no horizonte $>$ distância no meridiano $>$ distância no zênite $\left(d_{\mathrm{H}}>d_{\mathrm{M}}>d_{\mathrm{Z}}\right)$. Sabemos que uma distância maior deverá corresponder a um diâmetro aparente menor (e vice-versa). Nessas condições, o diâmetro aparente da Lua deverá ser máximo no zênite (distância mínima), um pouco menor no meridiano e, ainda, menor no horizonte. Trata-se de um resultado surpreendente, contrário às nossas expectativas e ao senso comum: a Lua junto ao horizonte apresenta um diâmetro 
aparente menor. Por que razão nos parece maior? É o que veremos neste artigo (veja-se a nota final 1 ).

Há algumas precauções a tomar nas medições eventualmente necessárias. No que se refere às medições de altura, convém referir que a refração atmosférica eleva a altura aparente dos astros, mas essa diferença é pequena para as medições absolutas de altura: tal elevação é de 34' para um astro no horizonte, $9,7^{\prime}$ a $5^{\circ}$ de altura, de $2,7^{\prime}$ a $20^{\circ}$, de $1^{\prime}$ ' a $45^{\circ}$ e é nula no zênite. Por esse motivo, não se fizeram correções de altura; no entanto, a refração diferencial a alturas muito baixas, muito perto do horizonte, contrai consideravelmente o diâmetro aparente da Lua na vertical: é por isso que os diâmetros aparentes se devem tomar na horizontal.

\section{Quantificando o problema}

Vistas as coisas do lado qualitativo, resta passar à análise quantitativa para saber quanto variam essas distâncias e saber se tais diferenças serão ou não significativas. A Fig. 2 mostra a Terra e a Lua com os seus tamanhos relativos à escala, mas a distância entre elas foi representada por metade do que deveria ser, para que coubesse nesta página. $\mathrm{O}$ ângulo $\alpha=\mathrm{BA} C$ é, na realidade, muito pequeno: para a distância média da Lua à Terra, $d_{\mathrm{m}}=384400 \mathrm{~km}$, e, para o raio terrestre médio $R=6373 \mathrm{~km}, \alpha=0,9498^{\circ} \approx 0,95^{\circ}$. Na verdade, o ângulo reto é o que tem vértice em $\mathrm{B}$ e o ponto $\mathrm{B}$ não está na vertical por cima de $\mathrm{C}$, mas um pouco mais para a direita, devido à obliquidade do segmento $\mathrm{BA}$ em relação ao segmento $\mathrm{CA}$. No entanto, essas diferenças são insignificantes e podemos considerar que BC e BA são praticamente do mesmo comprimento, pois $\cos 0,95^{\circ}=0,99986 \ldots \approx 1,00000$, com erro inferior a $0,0138 \%$. Assim sendo, as direções de BA e da CA podem ser vistas como se fossem paralelas, como se mostra na Fig. 3.

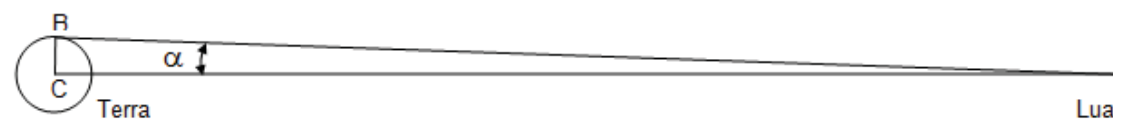

Fig. 2 - A Terra e a Lua. Para que tudo ficasse na escala nesta figura, tendo a Terra e a Lua as dimensões representadas, a distância entre os dois astros teria de ser o dobro da que aqui se mostra (mas já não caberia nesta página). Portanto, o ângulo a ainda é menor (praticamente metade) do que parece nesta ilustração. C e A indicam, respectivamente, o centro da Terra e o centro da Lua. 
O movimento aparente da Lua no céu (nascimento, passagem meridiana, ocaso) é principalmente devido à rotação da Terra (veja-se a nota final 2). A Fig. 3 mostra três posições do mesmo observador em relação à Lua, em três momentos distintos. Na posição B, o observador vê a Lua no horizonte; em D, vê-a no meridiano, a uma distância zenital $z$, correspondendo a uma altura $h=90^{\circ}-z$; na posição E, o observador vê a Lua no seu zênite (situação impossível para o território português).

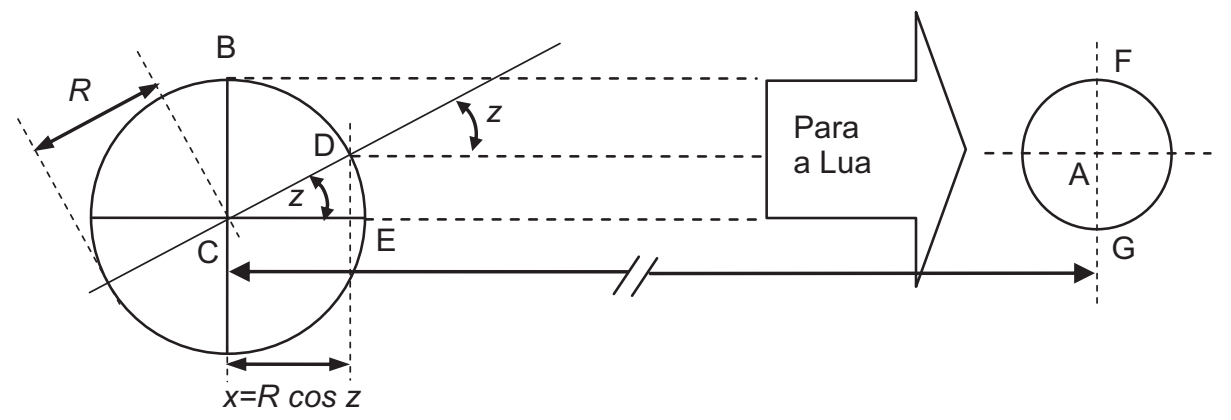

Fig. 3 - A Lua, vista pelo mesmo observador em três situações distintas. A distância entre o observador e a Lua mede-se até ao centro da Lua, dado que o limbo lunar, passando em $F$ e $G$, é praticamente coincidente com um círculo máximo perpendicular à linha de visão, por razões semelhantes às já indicadas para a Fig. 2.

Como podemos ver na Fig. 3, quando a Lua passa do horizonte $\left(h_{0}=0^{\circ}\right.$, posição B), para o meridiano do observador (posição D), ela aproxima-se deste uma distância $x$ dada por

$$
x=R \cos z, \text { ou seja } x=R \sin h,
$$

visto que $\cos z=\sin h$ (pois $h+\mathrm{z}=90^{\circ}$ ); $R$ é o raio terrestre médio: $R=6370 \mathrm{~km}$.

Quando a Lua passa no meridiano, a distância zenital lunar $(z)$ é mínima, correspondente a uma altura máxima $\left(h_{\mathrm{M}}\right)$. Assim, quando a Lua se eleva desde o horizonte até ao meridiano, a sua distância até ao observador diminui $x=R \sin h$. Ou seja,

$$
d_{\mathrm{M}}=d_{\mathrm{H}}-R \sin h_{\mathrm{M}}
$$

Escrevendo esta última expressão para uma altura genérica $h$, obtemos

$$
d=d_{H}-R \sin h
$$


que nos mostra claramente que $d$ é mínima quando $h=90^{\circ}$ (Lua no zênite do observador). A mesma Fig. 3 também mostra que $d_{\mathrm{M}}-d_{\mathrm{z}}=R(1-\sin h)$.

\section{Alguns casos particulares}

Para $h=45^{\circ}$ e $R=6373 \mathrm{~km}, x$ será aproximadamente $4506 \mathrm{~km}$. Portanto, a Lua no horizonte está $4506 \mathrm{~km}$ mais longe do observador do que quando está a ser vista no meridiano. Para a distância média entre centros dos dois astros de 384400 km, a distância do observador ao centro da Lua será:

a) com a Lua no horizonte, $d_{\mathrm{H}}=384400 \mathrm{~km}$;

b) com a Lua no meridiano, por exemplo, a $45^{\circ}$ de altura, a distância será $d_{45}=384400-6373 \sin 45^{\circ}=379894 \mathrm{~km}(\approx 379900 \mathrm{~km})$;

c) com a Lua no zênite (se o local do observador o permitir) $d_{\mathrm{Z}}=d_{\mathrm{M}}-R=384400-6373=378027 \mathrm{~km}(\approx 378000 \mathrm{~km})$;

esta situação não é viável no território português, onde a Lua nunca atinge o zênite.

A Lua, a $45^{\circ}$ de altura, está $4506 \mathrm{~km}$ mais perto do observador do que quando está a ser vista no horizonte. Posta tal diferença em percentagem, face à distância média da Lua à Terra $(384400 \mathrm{~km})$, será: $4506 / 384400=0,0117$, ou seja, a distância reduz-se em $1,17 \%$, quando a Lua passa do horizonte $\left(h_{0}=0^{\circ}\right)$ para $h=45^{\circ}$.

Dado que o diâmetro aparente da Lua é um ângulo pequeno, tal diâmetro aparente é inversamente proporcional à distância a que ela é observada. Para duas distâncias $d_{1}$ e $d_{2}$, sendo a Lua vista sob os diâmetros aparentes $\theta_{1}$ e $\theta_{2}$ (respectivamente), pode escrever-se:

$$
\frac{d_{1}}{d_{2}}=\frac{\theta_{2}}{\theta_{1}} .
$$

Dito de outro modo, eventualmente mais útil, se a Lua tiver o diâmetro aparente $\theta_{45}=0,500^{\circ}$ a $45^{\circ}$ de altura, com $d_{45}=379894 \mathrm{~km}$, a mesma Lua no horizonte, com $d_{\mathrm{H}}=384400 \mathrm{~km}$, será vista com um diâmetro aparente $\theta_{\mathrm{H}}$ tal que $(384400 / 379894)=\left(\theta_{\mathrm{H}} / \theta_{45}\right)$, ou seja, $\theta_{\mathrm{H}}=379894 \times 0,5 / 384400=0,494^{\circ}$. Note-se que o diâmetro aparente vertical da Lua é comprimido pela refração atmosférica terrestre, sobretudo a pequenas alturas, portanto é mais sensato tomar os diâmetros aparentes horizontais, que são imunes à refração diferencial. 


\section{Relação entre diâmetros aparentes da Lua para duas alturas quaisquer}

Também podemos prever a relação entre os diâmetros aparentes da Lua a duas quaisquer alturas diferentes, $h_{1}$ e $h_{2}>h_{1}$. Para isso, comecemos por escrever a equação 3 para os casos particulares $h_{1}$ e $h_{2}$ :

$$
d_{1}=d_{\mathrm{H}}-R \sin h_{1}
$$

$$
d_{2}=d_{H}-R \sin h_{2} .
$$

Entrando com os valores de $d_{1}$ e $d_{2}$ das equações 5 e 6 na equação 4 , obtemos imediatamente:

$$
\frac{d_{H}-R \sin h_{1}}{d_{H}-R \sin h_{2}}=\frac{\theta_{2}}{\theta_{1}},
$$

onde $d_{\mathrm{H}}$ pode ser tomada como a distância entre a Terra e a Lua no "momento" da observação (como já foi referido, em um intervalo de poucas horas, esta distância pouco se altera).

Se a Lua, vista junto ao horizonte, está, na realidade, mais longe do observador do que quando é observada a maiores alturas, o seu diâmetro aparente terá de ser menor, como acabamos de ver, mas de fato os observadores têm a convicção de que a veem maior. Deverá, pois, existir uma distorção da percepção, ilusão de óptica, ou efeito psicológico que contraria vantajosamente esta realidade objetiva. A aparente proximidade da Lua em relação ao horizonte, esteja ele livre (no oceano), pejado de árvores ou de prédios, forma uma referência que perturba a nossa percepção. Um exemplo desta distorção da percepção devido ao efeito de vizinhança pode ser visto na Fig. 4.

Se observarmos a Lua através de uma abertura circular (por exemplo, com $2 \mathrm{~cm}$ ou $3 \mathrm{~cm}$ de diâmetro), em uma folha de papel segura à distância de um braço estendido, verificamos que a Lua parece imediatamente menor: a "ilusão da Lua grande" desaparece, porque se eliminou o efeito de vizinhança do horizonte. Por outro lado, em uma noite de Lua cheia bem elevada sobre o horizonte, basta usar um vidro vulgar, colocado em frente aos olhos, para refletir a imagem da Lua como se ela estivesse junto ao horizonte, para vermos imediatamente que a Lua nos parece maior. 


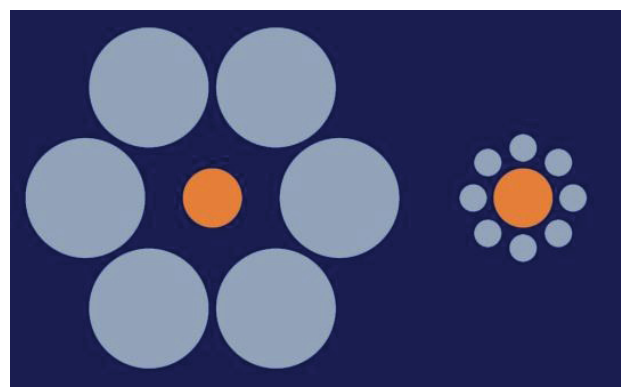

Fig. 4 - Esta figura mostra como o efeito de vizinhança distorce a nossa percepção do diâmetro do círculo laranja. Embora tal círculo seja rigorosamente igual à esquerda e à direita, as pessoas pensam que o círculo da direita é maior do que o da esquerda.

\section{Análise da variação do diâmetro aparente da Lua na noite de 29 para 20 de Março de 2011}

Neste perigeu especificamente, distância Terra-Lua foi

$d_{\text {per }}=356577 \mathrm{~km}$ (perigeu às 19:10 UT), com $R / d_{\text {per }}=1 / 55,95$.

Admitamos duas medições do diâmetro aparente horizontal da Lua, feitas para $h_{1}=7,5^{\circ}$ e $h_{2}=44,0^{\circ}$. Usando a equação 7 e considerando $d_{\mathrm{H}}=d_{\text {per, }}$, é lícito escrever:

$$
\frac{d_{\mathrm{per}}-R \sin h_{1}}{d_{\mathrm{per}}-R \sin h_{2}}=\frac{\theta_{2}}{\theta_{1}},
$$

e, portanto,

$$
\frac{356577-6373 \sin 7,5^{\circ}}{356577-6373 \sin 44^{\circ}}=\frac{\theta_{2}}{\theta_{1}},
$$

ou seja,

$$
\frac{\theta_{2}}{\theta_{1}}=1,0102
$$

Esse resultado significa que a razão (quociente) entre os diâmetros aparentes da Lua, na noite de 19 para 20 de março de 2011, para as alturas de $7,5^{\circ}$ e a $44^{\circ}$ será, previsivelmente, 1,0102. A validade desses cálculos e a pertinência das aproximações feitas poderão ser validadas pela medição concreta do quociente de 
tais diâmetros aparentes; podem ser usadas quaisquer unidades (graus, minutos de arco, pixéis, etc.), pois se trata de um quociente. O nosso colega e amigo Pedro Ré obteve essas imagens e mediu sobre elas, cuidadosamente, o diâmetro aparente horizontal da Lua. Será que os valores agora calculados se afastam significativamente dos resultados experimentais?

\section{Resultados experimentais}

Diâmetro aparente horizontal da Lua a 44,0 de altura: 1589 píxeis; diâmetro aparente horizontal da Lua a 7,5 de altura: 1585 píxeis (valores medidos por Pedro Ré). O resultado experimental do quociente dos diâmetros aparentes é

$$
\theta_{2} / \theta_{1}=1599 / 1585=1,0088 \text {. }
$$

O erro relativo do valor calculado, face ao valor efetivamente medido, foi, portanto,

$$
e_{\mathrm{r}}=\frac{|1,0102-1,0088|}{1,0088}=0,00139=0,14 \%<0,2 \% .
$$

Trata-se de um excelente acordo entre os valores calculados e os valores efetivamente medidos. As aproximações matemáticas feitas nos cálculos anteriores, que comportavam um erro relativo de apenas $0,0138 \%$, (10,1 vezes menor do que os $0,14 \%$ ) não viciam, portanto, os resultados agora obtidos.

\section{Conclusão}

Ao longo deste artigo, ficou claro que a Lua, quando vista junto ao horizonte, está efetivamente mais longe do observador do que quando a vemos mais alta. Tal circunstância, prevista pelo cálculo, é verificada por medições rigorosas sobre as imagens (feitas rigorosamente nas mesmas condições instrumentais). Torna-se, então, claro que a distorção de percepção pelo efeito de vizinhança leva a palma e consegue induzir o observador precisamente do contrário do que realmente acontece.

\section{Nota sobre distâncias e diâmetros aparentes}

Sendo a órbita da Lua muito perturbada, os sucessivos perigeus não são todos iguais, havendo, de tempos em tempos, perigeus extremamente próximos, como aconteceu em 19 de março de 2011, onde a distância da Lua à Terra atingiu o 
valor excepcionalmente pequeno de $356574 \mathrm{~km}$. Do mesmo modo, há, também, apogeus excepcionalmente afastados. No entanto, em termos médios, as distâncias e os diâmetros aparentes no sistema Terra-Lua seguem os valores indicados no quadro seguinte.

Alguns dados relevantes sobre distâncias e diâmetros aparentes no sistema TerraLua

\begin{tabular}{|l|l|l|l|}
\hline Grandeza & Perigeu & Distância média & Apogeu \\
\hline $\begin{array}{l}\text { Diâmetro aparente da } \\
\text { Lua vista da Terra }\end{array}$ & $33,60^{\prime}=0,560^{\circ}$ & $31,12^{\prime}=0,519^{\circ}$ & $29,43^{\prime}=0,491^{\circ}$ \\
\hline $\begin{array}{l}\text { Diâmetro aparente da } \\
\text { Terra vista da Lua }\end{array}$ & $124,44^{\prime}=2,07^{\circ}$ & $115,26^{\prime}=1,92^{\circ}$ & $109,00^{\prime}=1,82^{\circ}$ \\
\hline Distância Terra-Lua & $363299 \mathrm{~km}$ & $384400 \mathrm{~km}$ & $405507 \mathrm{~km}$ \\
\hline
\end{tabular}

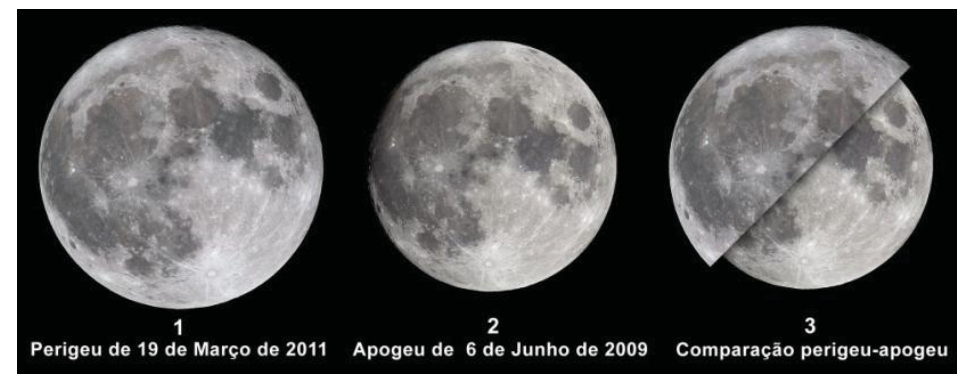

Fig. 5 - A variação da distância Terra-Lua, entre o perigeu e o apogeu, traduz-se em uma variação significativa do diâmetro aparente da Lua, em consequência da forma elíptica da sua órbita (variação média de 14\%). Adaptação realizada sobre imagens originais de Pedro Ré ( $<w w w$.astrosurf.com/re $\rangle)$.

\section{Agradecimento}

Agradeço a Pedro Ré as imagens da Fig. 5 e as medições sobre as suas fotografias comparativas obtidas na noite de 19-20 de março de 2011, elementos indispensáveis à comprovação experimental da validade dos cálculos que desenvolvi para este artigo. Estou-lhe grato pela disponibilidade desses dados e pelo interesse demonstrado nesta abordagem quantitativa. 


\section{Informação complementar}

Aspectos psicofisiológicos ligados à ilusão do tamanho aparente da Lua sobre o horizonte:

http://www.lhup.edu/ dsimanek/3d/moonillu.htm

http://www.lhup.edu/ dsimanek/3d/loony.htm

http://facstaff.uww.edu/mccreadd/intro9.htm

http://www.pnas.org/content/97/1/500.full.pdf

http://courses.washington.edu/psy333/lecture_pdfs/Week7_Day4.pdf

${ }^{(1)}$ No caso do Sol, à distância média $d_{\mathrm{S}}$ da Terra, a diferença de diâmetros aparentes, entre as posições no horizonte e no meridiano é praticamente indetectável, dado que, em média, $R / d_{\mathrm{S}} \approx 1 / 24000$.

(2) O movimento aparente médio da Lua (referindo-nos à sequência "nascimento, passagem meridiana, ocaso"), faz-se para oeste, devido à rotação da Terra, à razão de $15,04 \%$ h; e realiza-se simultaneamente para este (com pequenas variações de inclinação), à razão de $0,551 \%$ h, devido à translação lunar (horas de tempo solar médio). O movimento percebido, para oeste, é o que resulta destes dois. 